\title{
Spatial and temporal patterns of greenhouse gas emissions from Three Gorges Reservoir of China
}

\author{
Y. Zhao, B. F. Wu, and Y. Zeng \\ Key Laboratory of Digital Earth Science, Institute of Remote Sensing and Digital Earth, \\ Chinese Academy of Sciences, Beijing, China
}

Correspondence to: B. F. Wu (wubf@irsa.ac.cn)

Received: 1 September 2012 - Published in Biogeosciences Discuss.: 18 October 2012

Revised: 23 January 2013 - Accepted: 7 February 2013 - Published: 26 February 2013

\begin{abstract}
Anthropogenic activity has led to significant emissions of greenhouse gas (GHG), which is thought to play important roles in global climate changes. It remains unclear about the kinetics of GHG emissions, including carbon dioxide $\left(\mathrm{CO}_{2}\right)$, methane $\left(\mathrm{CH}_{4}\right)$ and nitrous Oxide $\left(\mathrm{N}_{2} \mathrm{O}\right)$ from the Three Gorges Reservoir (TGR) of China, which was formed after the construction of the famous Three Gorges Dam. Here we report monthly measurements for one year of the fluxes of these gases at multiple sites within the TGR region, including three major tributaries, six mainstream sites, two downstream sites and one upstream site. The tributary areas have lower $\mathrm{CO}_{2}$ fluxes than the main storage; $\mathrm{CH}_{4}$ fluxes in the tributaries and upper reach mainstream sites are relative higher. Overall, TGR showed significantly lower $\mathrm{CH}_{4}$ emission rates than most new reservoirs in temperate and tropical regions. We attribute this to the well-oxygenated deep water and high water velocities that may facilitate the consumption of $\mathrm{CH}_{4}$. TGR's $\mathrm{CO}_{2}$ fluxes were lower than most tropical reservoirs and higher than most temperate systems. This could be explained by the high load of labile soil carbon delivered through erosion to the Yangtze River. Compared to fossil-fuelled power plants of equivalent power output, TGR is a very small $\mathrm{GHG}$ emitter - annual $\mathrm{CO}_{2}$-equivalent emissions are approximately $1.7 \%$ of that of a coal-fired generating plant of comparable power output.
\end{abstract}

\section{Introduction}

The Three Gorges Dam, regarded as one of the world's largest hydropower dams, has been operating at full capacity since the end of 2008. The Three Gorges Reservoir (TGR) was subsequently formed after the impoundment. Although TGR plays an important role in flood control and increased navigability of the Yangtze River in addition to hydroelectric benefit, it has attracted tremendous attentions for the impact of TGR on ecosystem function and sustainability since the start of TGR construction (Stone, 2008; Fu et al., 2010). An emerging environment concern is greenhouse gas (GHG) emissions, including carbon dioxide $\left(\mathrm{CO}_{2}\right)$, methane $\left(\mathrm{CH}_{4}\right)$ and nitrous oxide $\left(\mathrm{N}_{2} \mathrm{O}\right)$ (Qiu, 2009).

It has long been recognized that the metabolism of allochthonous and autochthonous organic matter in reservoirs contributes to global GHG emission (St. Louis et al., 2000; Giles, 2006), whereas the accurate budget appears under much debate. For instance, the results from Brazilian hydroreservoirs suggested that GHG emissions could be equivalent to or even exceed those of fossil-fuelled power stations of the same power capacity (Fearnside, 2002). There are also observations showing low GHG emissions from reservoirs, despite being heavily disputed (DosSantos et al., 2006). The increasing line of evidences indicates that GHG emission kinetics might be dam-dependent (Tremblay et al., 2005). It seems plausible that TGR might produce GHG in a way different from those well-studied boreal (Duchemin et al., 1995; Soumis et al., 2004; Tremblay et al., 2005) and tropical reservoirs (Rosa et al., 2004; DosSantos et al., 2006; Guerin et al., 2006, 2008) due to its unique physic-chemical characteristics such as physical configuration and organic matter turnover. For example, TGR occupies a steep-sided gorge rather than a relatively shallow basin characteristic of the boreal and tropical reservoirs. The amount of organic matter that is the main precursor for GHG generation through microbial metabolisms is low. This is arguably ascribed to 
the fact that 1.2 million habitants in the small and narrow riverine floodplain were relocated and much of the vegetation and organic materials removed before the zone was flooded (Zhang and Lou, 2011). This situation is distinctly different from the Brazilian reservoirs where organic-matter-rich rainforests were inundated. In addition, the majority of allochthonous organic $\mathrm{C}$ input is primarily particulate organic carbon of eroded soil origin - for TGR about $2.5 \mathrm{M}$ tons $\mathrm{C}$ per year (Wu et al., 2007). In stark contrast, surface plant biomass boosts initial $\mathrm{CO}_{2}$ emissions in boreal reservoirs, whereas it is driven by sediment and pelagic respiration in the long term (Teodoru et al., 2011).

Despite its ecological and environmental significance, GHG emissions remains poorly understood in TGR. There are no emission rates of $\mathrm{N}_{2} \mathrm{O}$ and $\mathrm{CO}_{2}$ from TGR determined so far, and a better understanding of $\mathrm{CH}_{4}$ emission patterns is also required toward an accurate estimation of $\mathrm{CH}_{4}$ emission budget. Chen et al. (2009) reported relatively high emissions of $\mathrm{CH}_{4}$ from stands of predominant Scirpus triqueter $\left(14.9 \pm 10.9 \mathrm{mg} \mathrm{m}^{-2} \mathrm{~h}^{-1}\right)$ growing in temporary marshes formed in the drawdown zones of a tributary connected to the mainstream of TGR, leading to an estimated emission rate of $3.3 \mathrm{mg} \mathrm{CH}_{4} \mathrm{~m}^{-2} \mathrm{~h}^{-1}$ from the main body of the TGR. It implies that $20 \%$ of the total $\mathrm{CH}_{4}$ budget in TGR was emitted from riparian zone, which only occupied $10 \%$ of the total reservoir area. This budget appears to be drastically overestimated by a factor of $\sim 30$ in the main stem of TGR (Liu et al., 2011). It further highlights the importance of precise GHG emission patterns for a predictive understanding of GHG budget across temporal and spatial scales. Recent studies indeed have demonstrated that specific reservoir characteristics play a key role in the high emission of GHG (Sobek et al., 2012; DelSontro et al., 2011), but not well represented in some mathematic models (Barros et al., 2011). Such models will be of great help for decision making for future construction of hydropower reservoirs, and data collected from a range of circumstances can be of help in improving the accuracy and robustness of the model. Therefore, in this study we aim to determine the GHG seasonal emission patterns, and try to approach the GHG emission budget from TGR.

\section{Materials and methods}

\subsection{Site description}

The hydroelectric dam (Fig. 1) is located on the mainstream of the Yangtze River right upstream of Yichang city of Hubei Province. TGR is a typical valley-type reservoir with steep slopes on both sides of the river channel. Up to $96 \%$ of the TGR catchment is dominated by mountainous area, while only $4.3 \%$ plain area expands in the river valley. Annual average flow at Cuntan hydrological station, at the upstream end of the dam, is 11100 cumecs. The area of the catchment directly between Cuntan and the dam is about $58000 \mathrm{~km}^{2}$ and generates an additional annual average discharge to the Yangtze of 2800 cumecs. The water level of TGR can reach $175 \mathrm{~m}$ above sea level at total capacity, while the lowest storage holds $145 \mathrm{~m}$ to buffer the water from floods, mostly occurring in June every year. When at $175 \mathrm{~m}$ water level, TGR covers a water surface area of $1084 \mathrm{~km}^{2}$, including $782 \mathrm{~km}^{2}$ of mainstream and $302 \mathrm{~km}^{2}$ of tributary. Average depth of the reservoir is about $70 \mathrm{~m}$, and maximum depth in front of the dam is about $170 \mathrm{~m}$. The climate of the reservoir region is subtropical monsoon, with an annual mean temperature of $18^{\circ} \mathrm{C}$. The river flow peak occurs generally in late summer, coinciding with heavy rainfalls in the TGR catchment. The local annual rainfall is about $1100 \mathrm{~mm}$ and occurs mainly from May to September.

Since the end of 2008, TGR has been in full operational mode. It retains water from late September until early November, and high water levels were maintained up to late April in the following year. As the rainy season approaches, water level is drawn down gradually to $145 \mathrm{~m}$ in preparation for flood retention and mitigation. The interplay between water inflows and outflows for power generation, flood control, river navigation, and planned scouring of the bed sediment produces marked variations in the water residence times. These can be as short as 6 days at maximum design flows during the flood season and exceed 30 days in early summer when the dam is drawn down to its minimum water level $(145 \mathrm{~m})$. The modeled water velocity in the upper mainstream (310 to $660 \mathrm{~km}$ from Dam) remains above $2 \mathrm{~m} \mathrm{~s}^{-1}$ irrespective of the dam level. In the $310 \mathrm{~km}$ stretch closest to the dam wall, the modeled velocity is predicted to be about $0.5 \mathrm{~m} \mathrm{~s}^{-1}$.

\subsection{Greenhouse gases measurements}

Fluxes of $\mathrm{CO}_{2}, \mathrm{CH}_{4}$, and $\mathrm{N}_{2} \mathrm{O}$ through the water surface of the TGR reservoir were measured monthly from January to December of 2010 at four primary sampling regions (Fig. 1). Zigui (ZG, just upstream of the dam and $170 \mathrm{~m}$ deep at full storage level), Badong (BD, $75 \mathrm{~km}$ upstream and $110 \mathrm{~m}$ deep at full storage level) and Wanzhou (WZ, $282 \mathrm{~km}$ upstream and $80 \mathrm{~m}$ deep at full storage level) are longitudinally distributed along the mainstream. GHG determination was also performed at the Xiangxi River (XR), one of the biggest tributaries in the TGR catchment. The water storage of TGR results in a significant decline of the water velocity in the Xiangxi River, making it a lake-like region prone to algal blooms (Ye et al., 2006, 2007). At each site 4-5 independent flux measurements were made each month to take into account the variability of GHG fluxes. All sampling sites were away from the central shipping channel in consideration of the safety issues, and water depth at all sites exceeded $30 \mathrm{~m}$.

In addition, GHG fluxes were measured at four other mainstream sites in the further upper reach, i.e., Zhutuo (ZT), Cuntan (CT), Longxi (LX), Qingxi (QX), and in two major tributaries, i.e., Xiangjiang (XJ) and Daning (DN), which 


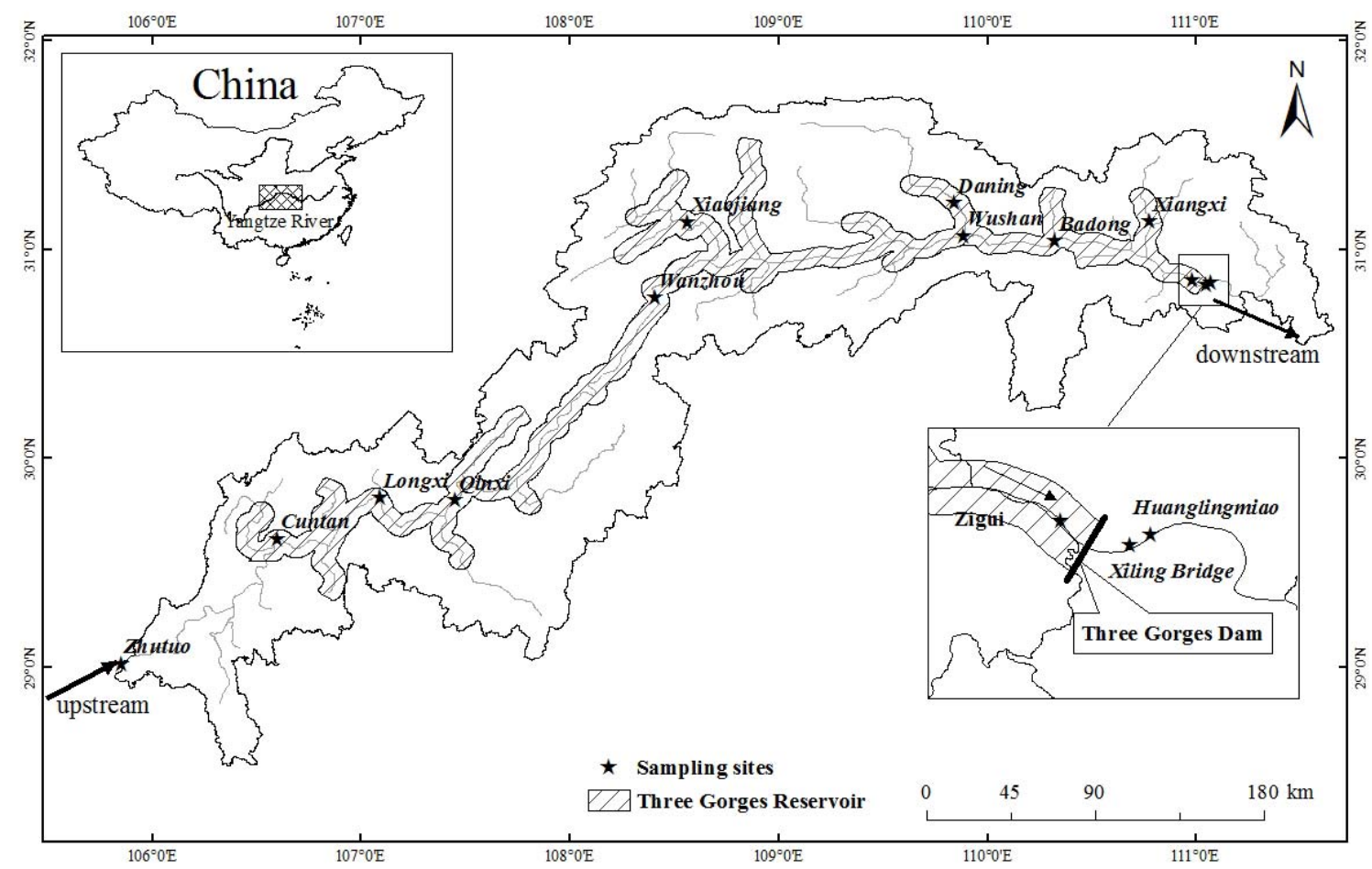

Fig. 1. Location of the Three Gorges Reservoir and sampling sites. Fluxes of $\mathrm{CO}_{2}, \mathrm{CH}_{4}$, and $\mathrm{N}_{2} \mathrm{O}$ through the water surface were measured from the following: seven mainstream sites, i.e., ZG (Zigui), BD (Badong), WZ (Wanzhou), QX (Qinxi), LX (Longxi), and CT (Cuntan); three tributaries, i.e., XR (Xiangxi River), DN (Daning) and XJ (Xiaojiang); two downstream sites, i.e., XLB (Xiling Bridge) and HLM (Huanglinmiao); and one upstream site of ZT (Zhutuo). Among them, ZG, BD, WZ and XR were measured monthly from January to December of 2010. All the other sites were measured from June 2010 to May 2011.

were inundated by the reservoir (Fig. 1). These mainstream sites represent distinctly different environmental conditions that may further affect GHG emission kinetics. For example, the ZT site is free from the reservoir influence. The CT site is in the interfluvial zone, formed as the reservoir water level is lowered from full storage level to $145 \mathrm{~m}$ above sea level, preparatory for the onset of the summer floods. All these sites were sampled monthly from June 2010 to May 2011.

GHG fluxes at downstream of the turbines were also measured at Xiling Bridge (XLB) and Huanglingmiao (HLM) (Fig. 1). These two sites were established specifically below the dam to explore the degassing component of the GHG emissions. Surface $\mathrm{CO}_{2}$ and $\mathrm{CH}_{4}$ fluxes were determined at XLB in the turbulent dam tailrace $4.9 \mathrm{~km}$ downstream of the dam, and at HLM, $7 \mathrm{~km}$ downstream, in the tail waters of Gezhouba dam (about $38 \mathrm{~km}$ downstream) and at the edge of the less turbulent shipping channel.

Monthly measurement was carried out for each site and the sampling time was controlled between 09:00 to 15:00 CST Sampling events were carried out in late every month and would last for a week or less; a small boat was used to transport between different sites and samplings were done on the same boat. At each site $\mathrm{CO}_{2}, \mathrm{CH}_{4}$ and $\mathrm{N}_{2} \mathrm{O}$ fluxes at the airwater interface were directly measured using a floating static chamber, usually with two replicate chambers deployed at each site. The chamber is a close-ended stainless steel cylinder, $60 \mathrm{~cm}$ in height and $30 \mathrm{~cm}$ in diameter, equipped with a dry battery-driven fan and a small lateral vent sealed by silicon septum. The fans were turned on before the chambers were deployed. When deployed, the chambers would float on the surface and chamber walls would extend $5 \mathrm{~cm}$ below the water surface. Three air samples from each chamber were manually collected with $100 \mathrm{ml}$ syringes at 0,10 and $20 \mathrm{~min}$ intervals after the deployment and stored in $500 \mathrm{ml}$ air-tight gas sampling bags.

\subsection{Fluxes determination}

Gas samples were transported to the laboratory and were analyzed at the Institute of Atmospheric Physics, Chinese Academy of Sciences. GHG concentrations were determined by a HP-4890D gas chromatograph (Agilent Corp.) according to the method as previously described (Xing et al., 2005). The standards were run before and after each set of samples to ensure the reproducibility of measurements. The detection limit of the gas chromatograph is $0.1 \mathrm{ppm}$ for $\mathrm{CH}_{4}$ and $\mathrm{CO}_{2}$ and $2 \mathrm{ppb}$ for $\mathrm{N}_{2} \mathrm{O}$, respectively, with analytical error on $\mathrm{du}-$ plicate standard samples of less than $1 \%$. Gas flux was calculated from a linear regression with gas concentration change 
within chamber versus time (IHA, 2010):

Flux $\left[\mathrm{mg} \mathrm{m}^{-2} \mathrm{~d}^{-1}\right]$

$=\frac{\text { Slope }\left[\mathrm{ppm} \mathrm{s}^{-1}\right] \times F_{1} \times F_{2} \times \text { Chamble Volume }\left[\mathrm{m}^{3}\right]}{\text { Chamber Surface }\left[\mathrm{m}^{2}\right]}$,

where slope is the value from linear regression of the gas concentration change within the chamber versus time, $F_{1}$ is a conversion factor from $\mathrm{ppm}$ to $\mathrm{mg} \mathrm{m}^{-3}$ for standard temperature and pressure for gas in air, and $F_{2}$ is a conversion factor of seconds into days. Only the sites where the gas concentration change had a linear regression coefficient over 0.8 were included in the calculation.

\subsection{Water environment samplings}

While collecting air samples, the surface water temperature $\left(T_{\mathrm{W}}\right)$, together with the temperature inside the chamber and air temperature, were measured with a JM624 portable digital thermometer equipped with 6-m-long probes. Water conductivity, and dissolved oxygen (DO) were measured in situ (at $0.5 \mathrm{~m}$ depth) with a DDB-3 (Leici Instrument, Shanghai, China) and a JPB-607 DO meter (Leici Instrument, Shanghai, China) respectively, Sesschi disk depth (SDD) was determined using Secchi disk. Water samples at 0.5-m depth were collected for laboratory analysis of chlorophyll $a$ (Chl $a)$, turbidity (Turb), total phosphorous (TP), total nitrogen (TN) and total organic carbon (TOC). The analysis of the water samples were performed by the Institute of Hydrobiology, Chinese Academy of Sciences (Yang et al., 2011).

As the temperature and DO structure in the water column would largely affect the GHG fluxes, especially $\mathrm{CH}_{4}$ fluxes, water column physic-chemical data were also collected (provided by the Bureau of Hydrology, Changjiang Water Resources Commission). The water temperature and DO concentrations of water profiles in front of the dam $(\mathrm{ZG}$, see Fig. 1) were measured monthly from July 2008 to June 2009. Water temperature was measured at 2-m intervals from top to the bottom of the reservoir, using the reversing thermometer method, while DO concentrations were sampled at the surface $(0.5 \mathrm{~m})$, bottom (about $175 \mathrm{~m}$ when the reservoir at its full capacity) and middle layer using Winkler titration method. Supplementary data on dissolved $\mathrm{CH}_{4}$ concentrations at different water depth at several sites of TGR were also collected and measured on 23 December 2011, using a headspace gas chromatography, which is described by IHA (2010).

\subsection{Data analysis and GHG budget calculation}

Mean $\mathrm{CO}_{2}, \mathrm{CH}_{4}$ and $\mathrm{N}_{2} \mathrm{O}$ fluxes were calculated by averaging the available replicate samplings at each site. Oneway analysis of variance (ANOVA) was used to analyze the differences in GHG fluxes from different sites. GHG fluxes were related to environmental variables by Pearson correla- tion analysis. These analyses were performed with the SPSS 15.0 statistical package.

To calculate the total GHG emissions (for $\mathrm{CO}_{2}, \mathrm{CH}_{4}$ and $\mathrm{N}_{2} \mathrm{O}$ respectively) from TGR, the reservoir water surface was divided into 25 subregions, representing 11 mainstream and 14 tributary regions. Water surface areas of each subregion at 135-, 145-, 156- and 175-m water level were extracted using a 10-m resolution digital elevation map. Linear relationships between water level and surface water area for each subregion were then established using a regression analysis and the surface area at different water levels was calculated. GHG emissions from TGR were calculated by multiplying the total averaged GHG fluxes from the sampling regions each month by the surface water area, GHG fluxes of five unmeasured mainstream subregions were interpolated using the values of the two nearest regions, and mean fluxes of the three measured tributaries were applied to the other tributaries. To calculate the annual emission of $\mathrm{CO}_{2}$ equivalents, $\mathrm{CH}_{4}$ and $\mathrm{N}_{2} \mathrm{O}$ emissions were added up to the total $\mathrm{CO}_{2}$ emission by multiplying their global warming potential (GWP) by 25 and 298, respectively. Equivalent $\mathrm{CO}_{2}$ emission per unit hydroelectricity was further calculated by dividing the annual power generation of TGR. ArcGIS 9.3 was used to manipulate the digital elevation map, while GHG emissions were calculated by the EXCEL 2007 software.

Total average $\mathrm{CO}_{2}$ and $\mathrm{CH}_{4}$ fluxes were estimated by dividing the total $\mathrm{CO}_{2}$ and $\mathrm{CH}_{4}$ emissions by the total surface area of TGR at full capacity $\left(1084 \mathrm{~km}^{2}\right)$; these results were compared to other reservoirs around the world. GHG emissions by other energy sources, like coal, fuel, diesel and natural gas, were calculated by multiplying the annual power generation of TGR by a carbon emission factor associated with each fuel and dividing by their energy efficiencies. These results allow TGR emissions to be compared with those produced by other energy sources.

\section{Results}

\subsection{Spatial and temporal variation of $\mathrm{CO}_{2}$ fluxes}

The results (Fig. 2) show that the surface waters at mainstream stations (WZ, BD and $\mathrm{ZG}$ ), are sources of $\mathrm{CO}_{2}$ to the atmosphere all year round with the $\mathrm{CO}_{2}$ fluxes higher in the warm season (Fig. 3). This is the period with high flow also. Fluxes at the 3 primary mainstream sites were consistently high (WZ, $126 \pm 110 \mathrm{mmol} \mathrm{m}^{-2} \mathrm{~d}^{-1} ; \quad \mathrm{BD}, \quad 126 \pm 80 \mathrm{mmol} \mathrm{m}^{-2} \mathrm{~d}^{-1}$; and $\left.\mathrm{ZG}, 104 \pm 87 \mathrm{mmol} \mathrm{m}^{-2} \mathrm{~d}^{-1}\right)$. The fluxes are less at upstream ZT $\left(88 \pm 57 \mathrm{mmol} \mathrm{m}^{-2} \mathrm{~d}^{-1}\right)$ and comparable to those at the 3 upper reach mainstream sites at QX $\left(127 \pm 57 \mathrm{mmol} \mathrm{m}^{-2} \mathrm{~d}^{-1}\right), \quad$ CT $\quad\left(170 \pm 97 \mathrm{mmol} \mathrm{m}^{-2} \mathrm{~d}^{-1}\right)$ and $\mathrm{LX}\left(175 \pm 150 \mathrm{mmol} \mathrm{m}^{-2} \mathrm{~d}^{-1}\right)$. Overall, the $\mathrm{CO}_{2}$ fluxes at mainstream sites are higher during the rainy/warm season. This finding suggests that $\mathrm{CO}_{2}$ production is related 

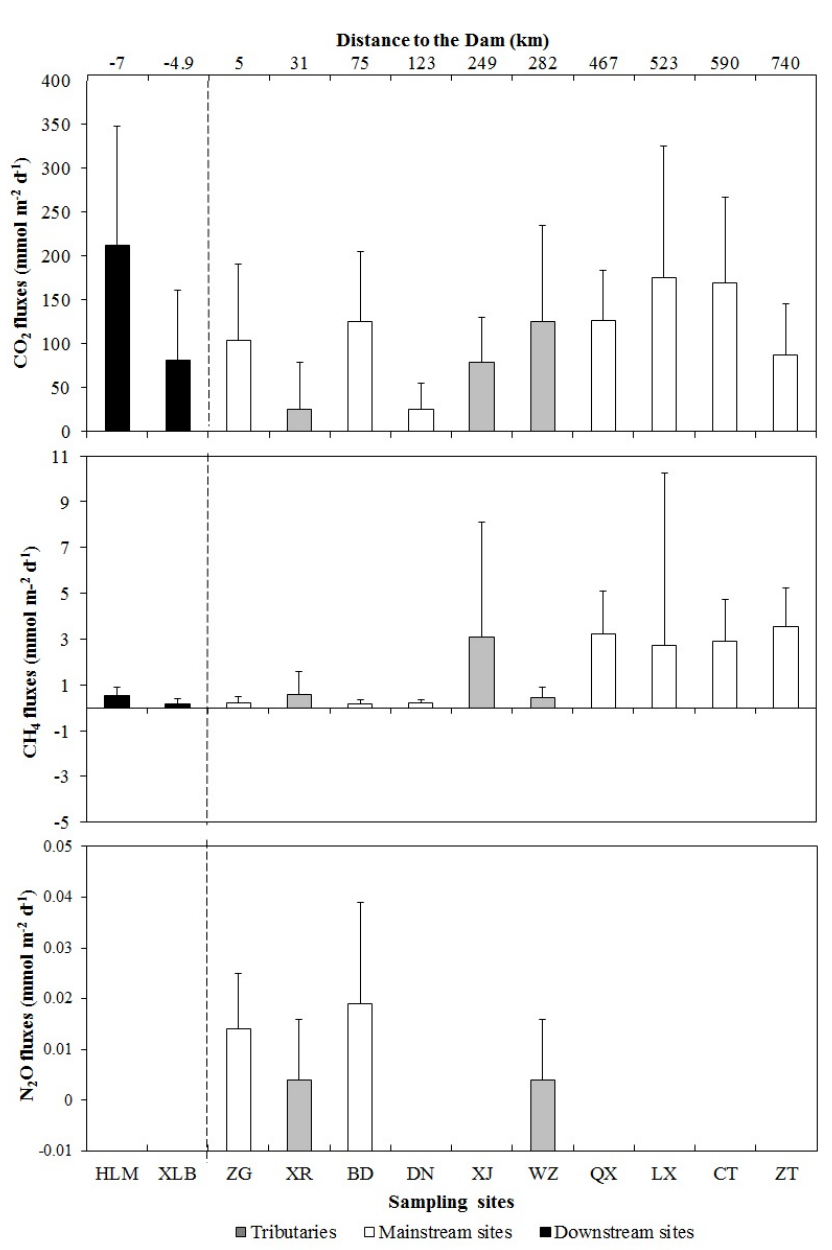

Fig. 2. Annual average GHG fluxes from different sampling sites of TGR. The dashed line demonstrates the location of the Three Gorges Dam. All the sampling sites are arranged according to their distance from the dam (labeled on the top $\mathrm{X}$-axis). For the sampled tributaries (XR, DN and $\mathrm{XJ})$, distance between the dam and tributary estuaries are used. Error bars indicated standard deviations with all the available replicates at each sites.

to the oxidation of incoming particulate organic carbon from the catchment, primarily soil organic carbon ( $\mathrm{Wu}$ et al., 2007). Relative to ZT (the representative upstream riverine site free of impact by the full reservoir waters), average mainstream $\mathrm{CO}_{2}$ flux $\left(137.5 \mathrm{mmol} \mathrm{m}^{-2} \mathrm{~d}^{-1}\right)$ have increased by $56 \%$. This is also higher than the modeled value $\left(62 \mathrm{mmol} \mathrm{m}^{-2} \mathrm{~d}^{-1}\right)$ based on the relationship between reservoir age ( $8 \mathrm{yr}$ for TGR) and $\mathrm{CO}_{2}$ fluxes (Barros et al., 2011).

The tributary of XR shows markedly contrasting behavior (Fig. 3). The $\mathrm{CO}_{2}$ fluxes were negative (i.e., from the atmosphere into the water) in March $\left(-7 \pm 2 \mathrm{mmol} \mathrm{m}^{-2} \mathrm{~d}^{-1}\right)$, June $\left(-26 \pm 12 \mathrm{mmol} \mathrm{m}^{-2} \mathrm{~d}^{-1}\right)$ and July $\left(-49 \pm 10 \mathrm{mmol} \mathrm{m}^{-2} \mathrm{~d}^{-1}\right)$, due to photosynthetic uptake by phytoplankton, and is consistent with the very high chlorophyll $a$ concentrations and a higher transparency compared to other regions. Because of the photosynthetic uptake there, XR has the lowest average annual $\mathrm{CO}_{2}$ flux $\left(25 \pm 54 \mathrm{mmol} \mathrm{m}^{-2} \mathrm{~d}^{-1}\right)$. The $\mathrm{CO}_{2}$ fluxes at the tributary regions were less than all the mainstream regions $(\mathrm{XJ}$, $79 \pm 52 \mathrm{mmol} \mathrm{m}^{-2} \mathrm{~d}^{-1} ; \mathrm{DN}, 25 \pm 30 \mathrm{mmol} \mathrm{m}^{-2} \mathrm{~d}^{-1}$ ) and $51 \%$ less than the upstream site of ZT. All the tributary sites have a large standard error (Fig. 2), reflecting a substantial seasonal variation of $\mathrm{CO}_{2}$ due to drawdown by photosynthesis during the summer season with still shallower waters favoring pelagic phytoplankton, and submerged and emergent vegetation growth leading to low $\mathrm{CO}_{2}$ fluxes. This stock of organic matter is subsequently submerged and oxidized during the high-water stage leading to high $\mathrm{CO}_{2}$ fluxes post-TGR reaching its full operational level.

The annual average $\mathrm{CO}_{2}$ fluxes from the downstream station closer to the dam (XLB: $81 \pm 80 \mathrm{mmol} \mathrm{m}^{-2} \mathrm{~d}^{-1}$ ) is less (though not statistically significant) than that at $\mathrm{ZG}$ immediately upstream of the dam, suggesting that about $22 \%$ of $\mathrm{CO}_{2}$ degassed due to the turbulence induced after the power house. However, significantly high emission rate of $212 \pm 136 \mathrm{mmol} \mathrm{m}^{-2} \mathrm{~d}^{-1}$ was observed at HLM station, which is only $2 \mathrm{~km}$ downstream from the dam. This implies that the degassing effect is likely constrained within limited waterbodies before the dam.

\subsection{Spatial and temporal variation of $\mathrm{CH}_{4}$ and $\mathrm{N}_{2} \mathrm{O}$ fluxes}

Annually, the four primary regions (ZG, BD, WZ, and XR) act as sources of atmospheric $\mathrm{CH}_{4}$ (Fig. 2). The annual average flux at XR was $0.57 \pm 1.00 \mathrm{mmol} \mathrm{m}^{-2} \mathrm{~d}^{-1}$, higher (though not statistically significant) than other three regions. WZ has the highest $\mathrm{CH}_{4}$ flux among the three mainstream sites, with an average flux of $0.42 \pm 0.49 \mathrm{mmol} \mathrm{m}^{-2} \mathrm{~d}^{-1}$. The values for $\mathrm{BD}$ and $\mathrm{ZG}$ are $0.18 \pm 0.16$ and $0.23 \pm 0.27 \mathrm{mmol} \mathrm{m}^{-2} \mathrm{~d}^{-1}$, respectively. Upstream, reservoir tail waters (CT, LX and QX) and tributary sites had relatively higher $\mathrm{CH}_{4}$ fluxes than the mainstream of the reservoir (Fig. 2), reflecting the greater autochthonous production in these areas as well as the greater deposition of reactive particulate organic matter entering TGR. Relative to ZT, the mainstream area had $59 \%$ lower $\mathrm{CH}_{4}$ flux and the tributary area $65 \%$ less. It seems that surface $\mathrm{CH}_{4}$ flux showed a decreasing trend with the increasing water depth of the sites tested in this study. When compared with the simulated result $\left(5.84 \mathrm{mmol} \mathrm{m}^{-2} \mathrm{~d}^{-1}\right)$ on the basis of the proposed model by Barros et al. (2011), $\mathrm{CH}_{4}$ fluxes at all sites are overestimated.

The annual average $\mathrm{CH}_{4}$ fluxes (Fig. 2) from the 2 downstream stations (XLB $0.17 \mathrm{mmol} \mathrm{m}^{-2} \mathrm{~d}^{-1}$ and HLM $0.53 \mathrm{mmol} \mathrm{m}^{-2} \mathrm{~d}^{-1}$ ) are slightly higher than fluxes at ZG immediately above the dam. The water $\mathrm{CH}_{4}$ concentrations are not significantly different, suggesting that the losses through the turbines (i.e., by degassing) are limited and that the flux 

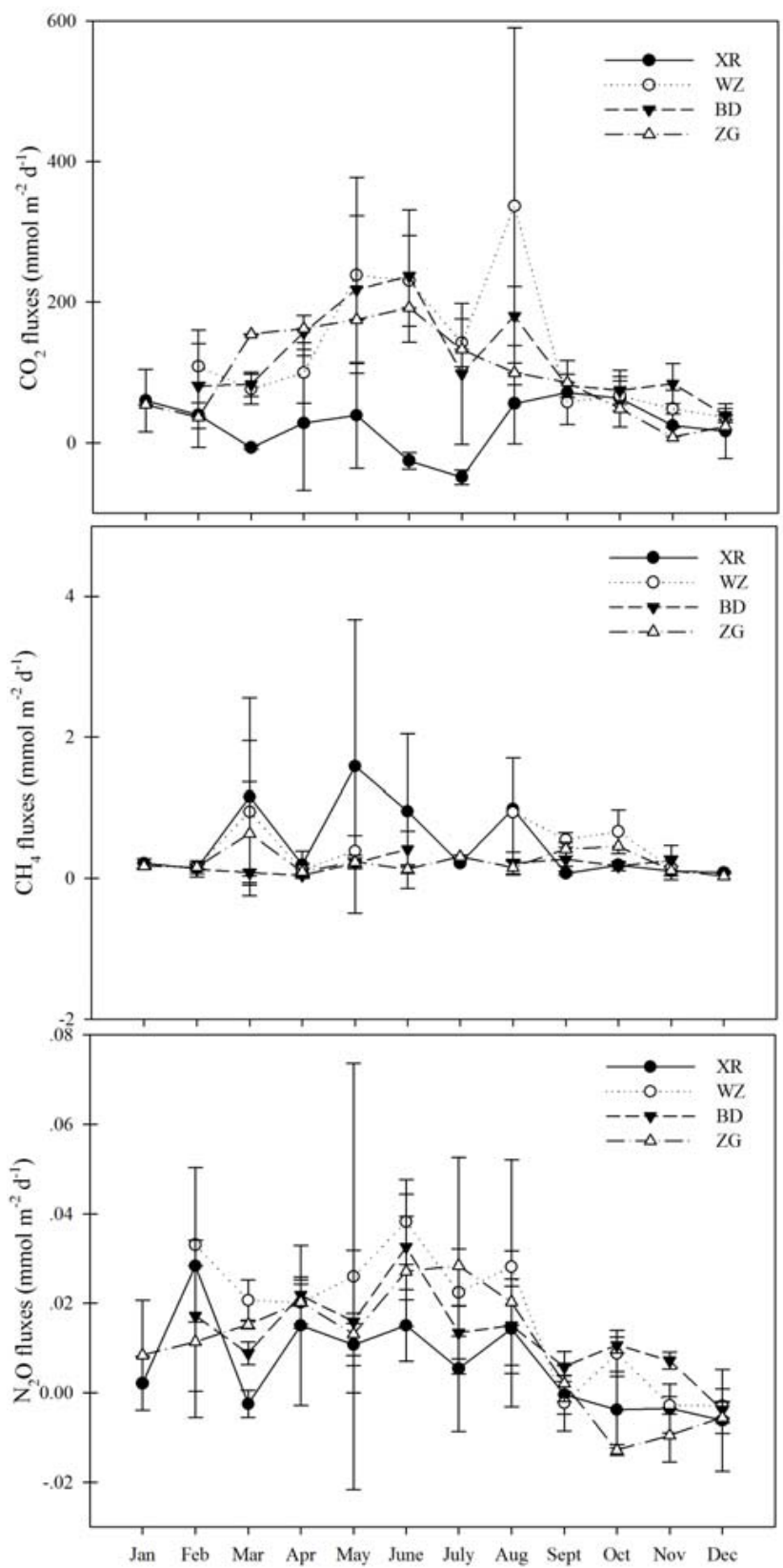

Fig. 3. Seasonal variations of GHG fluxes from three mainstream sites (WZ, BD, ZG) and a tributary of XR. The error bars indicate the standard deviations among the replicates at each site in each month. All designations are the same as those in Fig. 1.

differences arise from much higher turbulence in the zone immediately downstream of the dam (Vachon et al., 2010).

$\mathrm{N}_{2} \mathrm{O}$ fluxes were much lower compared to $\mathrm{CO}_{2}$ and $\mathrm{CH}_{4}$ fluxes (Fig. 3); the total average fluxes at the mainstream and Xiangxi River were $12 \pm 15$ and $4 \pm 12 \mathrm{nmol} \mathrm{m}^{-2} \mathrm{~d}^{-1}$, respectively, consistent with the suggestion of very small $\mathrm{N}_{2} \mathrm{O}$ fluxes from freshwater reservoirs (Huttunen et al., 2003).
Even after conversion to equivalent GHG fluxes $(\times 298)$ the $\mathrm{N}_{2} \mathrm{O}$ contribution to total reservoir GHG flux is negligible.

\subsection{Water environment dynamics and their relationships with GHG fluxes}

The temperature of the TGR surface water varies from 9.6 to $32^{\circ} \mathrm{C}$ and there were no significant differences between the four sampling water regions (Fig. 4a). TGR had slightly basic waters with a mean pH value of 8.04 (Fig. 4b). Chl $a$ concentration was relatively low from January to February and October to December in the waterbody of TGR. During the rest of the year, Chl $a$ concentration in Xiangxi River was much higher than in the mainstream and it reached a peak value of $40.46 \mu \mathrm{g} \mathrm{L}^{-1}$ in June (Fig. 4c). DO in surface water showed a similar spatial-temporal variation with the Chl $a$ concentration, indicating the impact of photosynthesis on DO concentration (Fig. 4d). SDD reflected the content of suspended sediments. Low values occurred during the rainy season (from May to September), mainly due to the input of large particles via the surface runoff in the drainage basin (Fig. 4e). TOC in the TGR was relatively low for most of the sampling period, but rose during the rainy season (Fig. 4f).

To gain insights into the possible mechanisms controlling GHG fluxes, we examined the correlations between these environmental parameters and the measured GHG fluxes (Table 1). Significant relationships existed between $\mathrm{CO}_{2}$ fluxes and water environment variables like Chl $a(r=-0.368, n=$ $158, p=0.000)$, DO $(r=-0.369, n=158, p=0.000)$, SDD $(r=-0.261, n=158, p=0.001)$ and Turb $(r=$ 0.241, $n=129, p=0.006)$. Significant correlation also observed between $\mathrm{CH}_{4}$ fluxes and Chl $a(r=0.237, n=145$, $p=0.004)$ and DO $(r=0.260, n=145, p=0.002) . \mathrm{N}_{2} \mathrm{O}$ flux is high correlated with DO, SDD and TOC.

\section{Discussion}

\subsection{Patterns of GHG emission from the Three Gorges Reservoir}

According to the monthly measurements, $\mathrm{CO}_{2}$ fluxes at the 6 mainstream sites showed no significant difference $(p=$ $0.154)$, but there were significant differences $(p=0.003)$ in the sampled tributaries. Significant difference was also found between $\mathrm{XR}$ and other mainstream sites such as ZG ( $p=$ $0.005), \mathrm{BD}(p=0.000)$ and $\mathrm{WZ}(p=0.001)$. For $\mathrm{CH}_{4}$, significant differences were both observed among the sampled tributaries $(p=0.049)$ and mainstream sites $(p=0.010)$. These distinctions, together with the seasonal patterns of GHG fluxes, indicated that the fluxes at different parts of the reservoir were affected by a set of factors.

The strong negative correlation between $\mathrm{CO}_{2}$ flux and Chl $a$ concentration suggests that photosynthetic uptake of $\mathrm{CO}_{2}$ reduces the net flux. This could be a major reason leading to lower $\mathrm{CO}_{2}$ fluxes in the tributaries, especially in XR. 
Table 1. Correlation between GHG fluxes and water environment variables at $0.5-\mathrm{m}$ depth of the TGR. The variables including surface water temperature (Tw), Sesschi disk depth (SDD), chlorophyll $a(\mathrm{Chl} a), \mathrm{pH}$, dissolved oxygen (DO), turbidity (Turb) and total organic carbon (TOC).

\begin{tabular}{lllllllc}
\hline & Tw & SDD & \multicolumn{1}{c}{ Chl $a$} & pH & \multicolumn{1}{c}{ DO } & \multicolumn{1}{c}{ Turb } & \multicolumn{1}{c}{ TOC } \\
\hline $\mathrm{CO}_{2}$ & 0.142 & $-0.261^{2}$ & $-0.368^{2}$ & -0.148 & $-0.369^{2}$ & $0.241^{2}$ & \multicolumn{1}{c}{0.116} \\
$\mathrm{CH}_{4}$ & 0.063 & -0.145 & $0.237^{2}$ & 0.048 & $0.260^{2}$ & -0.041 & $-0.170^{1}$ \\
$\mathrm{~N}_{2} \mathrm{O}$ & 0.054 & $-0.245^{2}$ & -0.034 & -0.038 & $-0.294^{2}$ & $0.303^{2}$ & $0.228^{2}$ \\
\hline
\end{tabular}

1 Correlation is significant at the 0.05 level.

2 Correlation is significant at the 0.01 level.

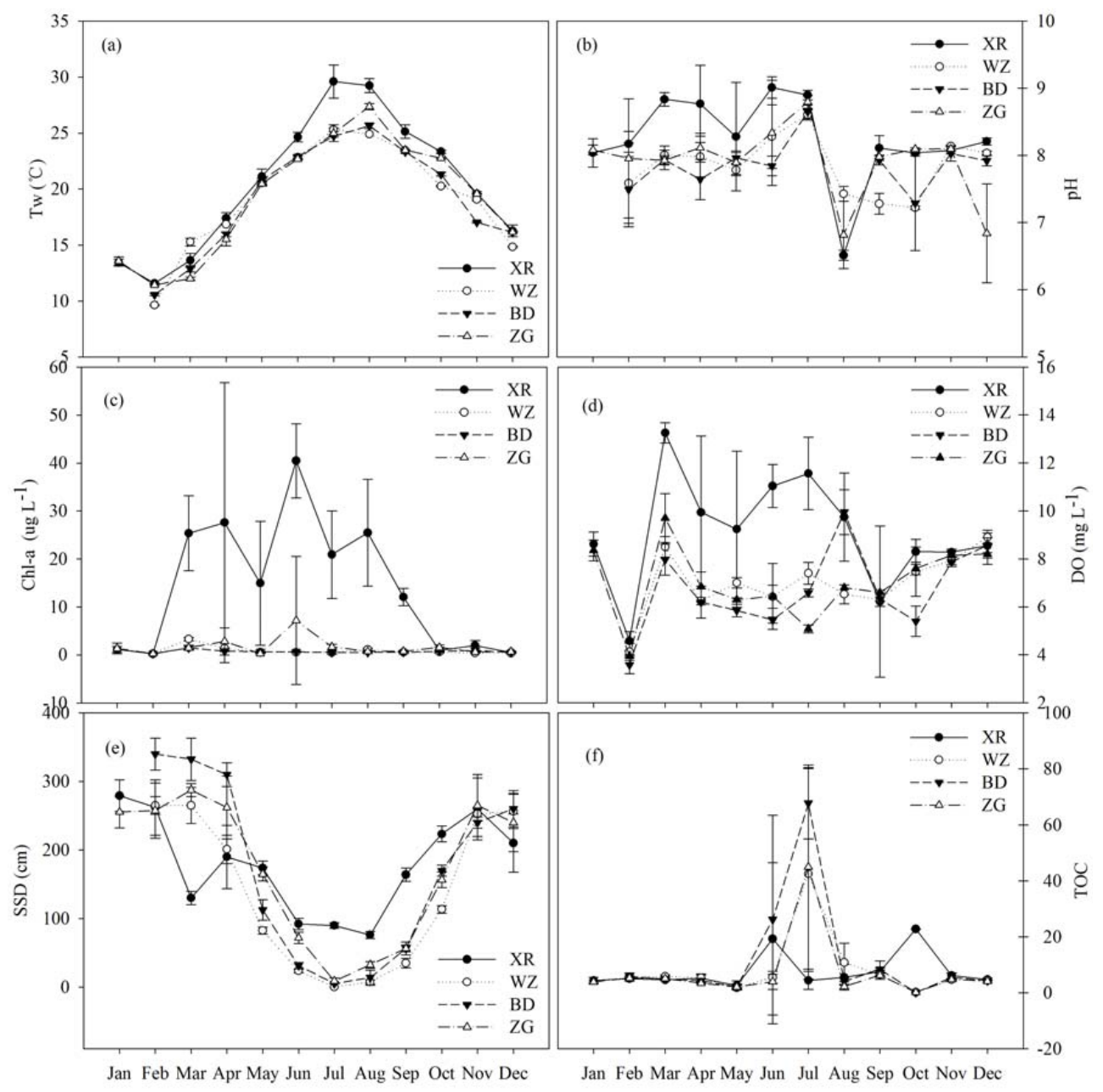

Fig. 4. Seasonal variation of water quality parameters from January to December. All designations are the same as those in Fig. 1.

This observation agrees with the temporal trends observed, with the Chl $a$ concentration reaching a maximum at summer low-water period (Fig. 4). XR is one of the tributary regions prone to algal blooms post-dam completion due to the dramatically reduced current velocity and the excess input of nutrients. The strong negative correlation between DO and $\mathrm{CO}_{2}$ flux also is consistent with the influence of algal photo- synthesis processes on $\mathrm{CO}_{2}$ fluxes as $\mathrm{O}_{2}$ is produced simultaneously by the same processes that are removing $\mathrm{CO}_{2}$.

The observed negative correlation between transparency and $\mathrm{CO}_{2}$ fluxes reflects the key role of allochthonous particulate organic carbon in reservoir $\mathrm{CO}_{2}$ production, especially at the three mainstream sampling regions. Low transparency ( $<1 \mathrm{~m}$ ) occurs from May to September (Fig. 4), when major inflows as well as rainfall events happen in the region. 
The input of particles from the drainage basin through surface runoff decreases the transparency, but increases both dissolved and particulate allochthonous carbon (Oelbermann et al., 2011). As precursors for heterotrophic organisms, these degradable organic carbons enhance $\mathrm{CO}_{2}$ production, despite the dilution effects of the higher flows. Similar findings were noted in several lakes and reservoirs in Finland (Huttunen et al., 2003), where the authors observed that both the autochthonous and allochthonous carbon sources were important in the GHG emissions from reservoirs. This result confirms earlier work suggesting that freshwater lakes, rivers and reservoirs play a major role in the transfer of terrestrially fixed carbon to the atmosphere, although they account for less than 0.4 percent of the earth's surface (Tremblay et al., 2005). Water temperature plays an important role in these processes also. Higher water temperature during the period results in higher rates of decomposition of organic carbon, and this temperature dependence explains also why $\mathrm{CO}_{2}$ fluxes were much lower in colder seasons (Fig. 3).

None of the analyzed variables showed high correlation with $\mathrm{CH}_{4}$ fluxes, except for $\mathrm{Chl} a$ at statistically significant level $(p<0.01)$. This is consistent with much of the autochthonous production contributing to the formation of sediment anoxia due to the highly reactive phytoplankton detritus leading to conditions appropriate for $\mathrm{CH}_{4}$ production. Earlier work noted that in eutrophic reservoirs with anoxic hypolimnion, a large amount of organic carbon fixed by photosynthesis was recycled as $\mathrm{CH}_{4}$ (Tremblay et al., 2005). Emission of $\mathrm{CH}_{4}$ is contingent on the creation of anoxic zones within the sediments (Sobek et al., 2012) and the absence of other factors limiting $\mathrm{CH}_{4}$ emissions from the surface. These limiting factors include an oxygenated water column where oxidation of dissolved $\mathrm{CH}_{4}$ may occur (Sobek et al., 2012) and deep waters promoting the dissolution of $\mathrm{CH}_{4}$ bubbles thus reducing the "direct" bubble flux to the surface and prolonging the time dissolved $\mathrm{CH}_{4}$ is exposed to oxidation in the water column. As for TGR, reservoir operation made the water column not only well mixed top to bottom for most of the year, but also the complete water column has high DO concentrations ( $>6 \mathrm{mg} \mathrm{L}^{-1}$, Fig. 5). Only in April and May is there substantial temperature stratification in mainstream (Fig. 6) and tributaries (Yu and Wang, 2011), The high DO concentrations even in the deepest parts of the TGR storage minimize the scope for sediment anoxia (Bastviken et al., 2006). The great water depth favors dissolution of the bubbles emitted from the sediment before they reach the surface (McGinnis et al., 2006), thus the surface emission of $\mathrm{CH}_{4}$ is relative low, especially in the mainstream sites like $\mathrm{BD}, \mathrm{WZ}$, ZG.

The relative higher $\mathrm{CH}_{4}$ fluxes at the tributaries may also help to analyze the characteristic of the drawdown zone on $\mathrm{CH}_{4}$ emissions, as the potential littoral zone of the mainstream of TGR is quite limited due to the steep-sided configuration; the largest quasi-littoral zone in the TGR forms along the tributaries with a smaller zone extending along the

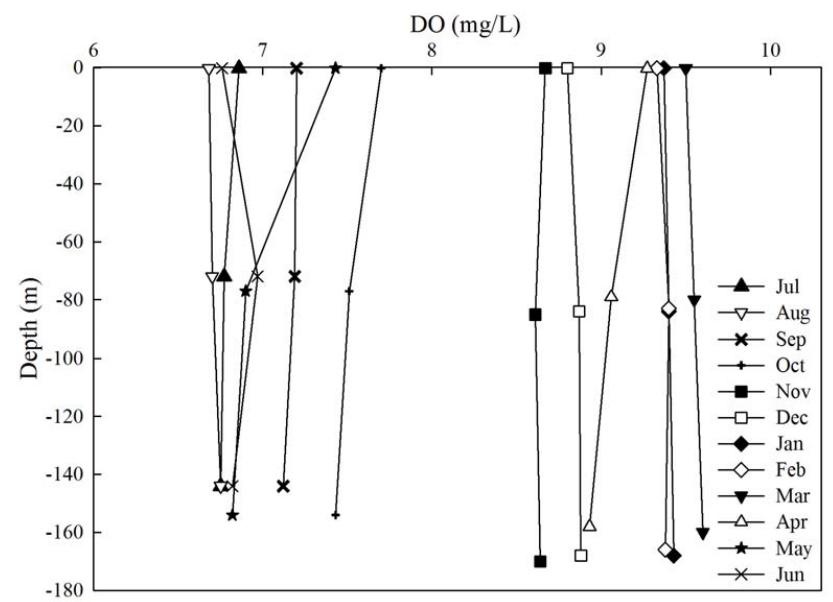

Fig. 5. Seasonal variation of DO concentrations at surface water $(0.2 \mathrm{~m})$, bottom layer $(0.5 \mathrm{~m}$ above the sediment $)$ and the middle layer in front of the dam (ZG site) from July 2008 to June 2009.

edges of the mainstream as the water is progressively drawn down. The drawdown zone of a reservoir is generally considered to be a "hot spot" for $\mathrm{CH}_{4}$ emissions (Bergstrom et al., 2007). Clearly, it forms a quasi-littoral zone where riparian vegetation growth can occur and organic-rich sediment is deposited. On refilling, microbial metabolism of the organic carbon plus reduced oxygen supply leads to anoxic sediments and production of $\mathrm{CH}_{4} \cdot \mathrm{CH}_{4}$ fluxes will rise in the still wetted regions here as water shallows; however, much of this area is scoured out during the first major flood event and $\mathrm{CH}_{4}$ fluxes then fall back closer to those elsewhere in the mainstream (Fig. 3). The tributaries, on the other hand, are less subject to scouring, as the power of the tributary remains the same, while the area of the wetted zone subject to drawdown is increased due to the raised water level. Thus, in the tributaries the drawdown area takes on much of the character of a quasi-permanent littoral deposition zone with continuing accumulation of organic-rich sediments occurring over repeated reservoir emptying and filling cycles. This conceptual description explains the phenomenon described by Bergstrom et al. (2007) and the high $\mathrm{CH}_{4}$ fluxes observed from XJ, DN, and XR in this study and previously reported in another TGR tributary by Chen et al. (2009). The $\mathrm{CH}_{4}$ fluxes we measured at these tributary sites are considerably low, however, than those reported by Chen et al $\left(5.8 \mathrm{mmol} \mathrm{m}^{-2} \mathrm{~d}^{-1}\right)$. The littoral $\mathrm{CH}_{4}$ fluxes demonstrated significantly spatial variations, suggesting that caution needs to be fully considered in extrapolating these fluxes to the reservoir as a whole, and to the total littoral area as previously reported (Qiu, 2009).

The seasonal variations of GHG fluxes across geologically distinct sites highlight the importance of samplings from regions representative of spatial-temporal dynamics in TGR. For instance, the relatively small areas showed a 


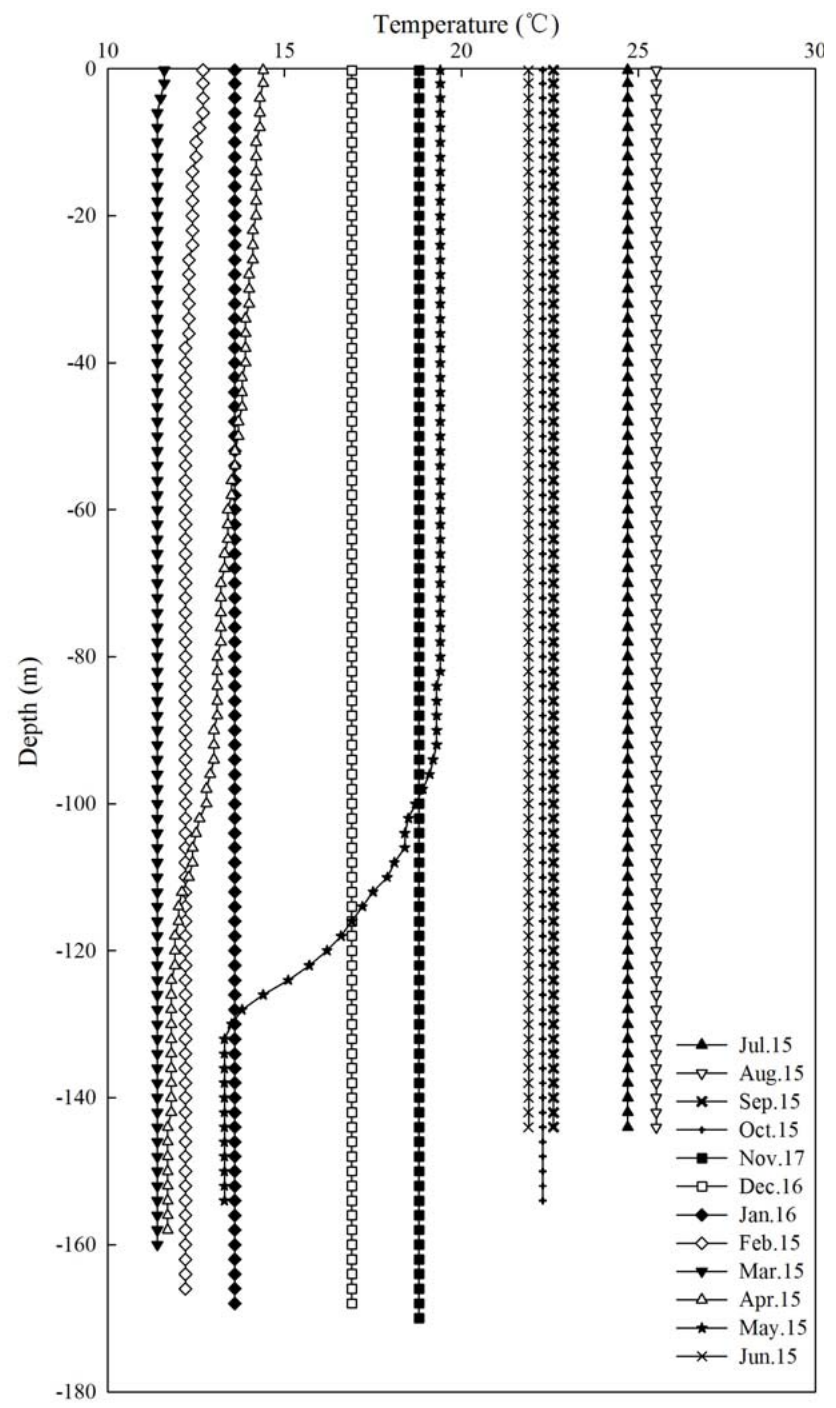

Fig. 6. Temperature profile in front of the dam (ZG site), from July 2008 to June 2009. Minor stratification in April and strong stratification in May are observed.

disproportionate effect on total GHG emissions, in particular for the tributaries and interfluvial areas. Specific operational factors (water depth, high oxygen content due to the turbulent conditions, and short residence time) cause TGR to fall well outside the predictions of $\mathrm{CH}_{4}$ emissions with age (Barros et al., 2011). The existence of other systems such as Lake Wohlen (DelSontro et al., 2011) that also depart significantly from such predictions suggests that a more nuanced approach is needed in predicting GHG emissions from hydropower reservoirs.

\subsection{Comparison with other reservoirs and other energy sources}

In 2010 our results indicated that about $1.3 \times 10^{6} \mathrm{tCO}_{2}$, $6.2 \times 10^{3} \mathrm{tCH}_{4}$ and $128 \mathrm{t} \mathrm{N}_{2} \mathrm{O}$ escaped from the reser-
Table 2. GHG emissions by thermal power plants assuming the generating power output equivalent to that of the Three Gorges power station in 2010 .

\begin{tabular}{lrrrr}
\hline Fuels & $\begin{array}{r}\text { Emission } \\
\text { factor }^{\mathrm{a}} \\
\left(\mathrm{tC} \mathrm{MWh}^{-1}\right)\end{array}$ & $\begin{array}{r}\text { Effi- } \\
\text { ciency }^{\mathrm{b}} \\
(\%)\end{array}$ & $\begin{array}{r}\text { Emis- } \\
\text { sions }^{\mathrm{c}} \\
(\mathrm{tC})\end{array}$ & $\begin{array}{r}\% \text { of other } \\
\text { energy } \\
\text { sources }\end{array}$ \\
\hline TGR & - & - & 411491 & - \\
Natural gas & 0.05508 & 44 & 10561590 & 3.9 \\
Diesel oil & 0.07272 & 34 & 18045254 & 2.3 \\
Fuel oil & 0.07596 & 34 & 18849251 & 2.2 \\
Coal & 0.09288 & 33 & 23746320 & 1.7 \\
\hline
\end{tabular}

${ }^{\mathrm{a}}$ Measure of average carbon emitted by each fuel, expressed in $\mathrm{tCMWh}^{-1}$, data are retrieved from IPCC Emission Factor Database (EFDB), 1997.

${ }^{\mathrm{b}}$ Stands for energy efficiency of power generation, data are cited from Graus et al. (2007).

${ }^{c}$ Annual power generation of TGR $\times$ emission factor / fuel efficiency (DosSantos et al., 2006).

voir surface water into the atmosphere. Taking into account the global warming potential of $\mathrm{CH}_{4}$ and $\mathrm{N}_{2} \mathrm{O}$, the annual emission of $\mathrm{CO}_{2}$ equivalents was estimated to be $1.5 \times 10^{6} \mathrm{t}$. Compared to the $1.6 \times 10^{9} \mathrm{t}$ of carbon emissions of China in 2006 (James, 2009), GHG emission from TGR is negligible. In 2010 the Three Gorges power station generated a total of $8.437 \times 10^{10} \mathrm{kWh}$. Thus, TGR generated $17.88 \mathrm{~g} \mathrm{CO}_{2 \text { equiv }} \mathrm{kWh}^{-1}$, which means $4.8 \times 10^{-3} \mathrm{tC} \mathrm{MWh}^{-1}$. The equivalent emissions produced by thermal power plants burning different fuels such as coal, fuel oil, and natural gas with different technology efficiency levels were calculated using emission factors from the IPCC Emission Factor Database (Table 2). Total GHG emissions from TGR were much lower than the annual $\mathrm{CO}_{2}$ emissions from other power sources ( $1.7 \%$ of coal, and $3.9 \%$ of natural gas).

The total averaged fluxes from the TGR were $96.18 \mathrm{mmol} \mathrm{m}^{-2} \mathrm{~d}^{-1}$ for $\mathrm{CO}_{2}$ and $0.32 \mathrm{~mol} \mathrm{~m}^{-2} \mathrm{~d}^{-1}$ for $\mathrm{CH}_{4}$. Compared with other storages (Table 3), TGR showed significantly lower $\mathrm{CH}_{4}$ emissions than most of the newly constructed reservoirs in temperate and tropical regions. We attribute this to less-inundated biomass, and deep well-mixed, and oxygenated water in TGR. $\mathrm{CO}_{2}$ emissions were higher than most temperate reservoirs, but still lower than most tropical reservoirs. These observations might be explained in part by the high carbon load to TGR. The Yangtze River system had higher organic content and exports more organic carbon than some comparable large rivers such as Mississippi, but less than that of the Amazon River (Wu et al., 2007).

\subsection{Uncertainties}

As noted earlier we focus on gross surface fluxes here and do not differentiate between diffusive and bubble fluxes. It is possible, however, to infer from the number of discontinuities in the individual plots of the chamber measurements 
Table 3. $\mathrm{CO}_{2}$ and $\mathrm{CH}_{4}$ emissions of per unit installed power generation capacity.

\begin{tabular}{|c|c|c|c|c|c|c|c|}
\hline Reservoir & Location & Climate & $\begin{array}{r}\text { Area } \\
\left(\mathrm{km}^{2}\right)\end{array}$ & $\begin{array}{l}\text { Installed } \\
\text { Capacity } \\
(\mathrm{MW})\end{array}$ & $\begin{array}{r}\mathrm{CO}_{2} \\
\text { fluxes } \\
\left(\mathrm{mmol} \mathrm{m}^{-2} \mathrm{~d}^{-1}\right)\end{array}$ & $\begin{array}{r}\mathrm{CH}_{4} \\
\text { fluxes } \\
\left(\mathrm{mmol} \mathrm{m}^{-2} \mathrm{~d}^{-1}\right)\end{array}$ & References \\
\hline Petit Saut & French Guiana & tropical & 350 & 115 & 102 & 0.7 & Guerin et al. (2006) \\
\hline Balbina & Brazil & tropical & 2360 & 250 & 76 & 2.1 & Guerin et al. (2006) \\
\hline Samuel & Brazil & tropical & 540 & 216 & 976 & 5 & Guerin et al. (2006) \\
\hline Tucurui & Brazil & tropical & 2850 & 8370 & 237.11 & 12.01 & DosSantos et al. (2006) \\
\hline Itaipu & Brazil & tropical & 1350 & 14000 & 27.39 & 0.78 & DosSantos et al. (2006) \\
\hline Laforge 1 & Canada & boreal & 1288 & 878 & 46.86 & 1.71 & Tremblay et al. (2005) \\
\hline Laforge 2 & Canada & boreal & 260 & 319 & 18.93 & 0.47 & Tremblay et al. (2005) \\
\hline La Grande 3 & Canada & boreal & 2420 & 2418 & 38.80 & 0.51 & Tremblay et al. (2005) \\
\hline La Grande 4 & Canada & boreal & 765 & 2779 & 26.77 & 0.68 & Tremblay et al. (2005) \\
\hline Robert-Bourassa & Canada & boreal & 2835 & 5616 & 38.77 & 0.49 & Tremblay et al. (2005) \\
\hline F. D. Roosevelt & United States & temperate & 306 & 6809 & -9.89 & 0.14 & Soumis et al. (2004) \\
\hline Dworshak & United States & temperate & 37 & 400 & -23.41 & 0.21 & Soumis et al. (2004) \\
\hline Wallula & United States & temperate & 157 & 1120 & -9.48 & 0.53 & Soumis et al. (2004) \\
\hline Shasta & United States & temperate & 77 & 629 & 31.02 & 0.69 & Soumis et al. (2004) \\
\hline Lokka & Finland & boreal & 417 & $1849^{*}$ & 35 & 2.1 & Huttunen et al. (2003) \\
\hline TGR & China & subtropical & 1084 & 22500 & 96.18 & 0.32 & This study \\
\hline
\end{tabular}

* Estimated from annual production of Lokka reservoir (675 GWh).

when a bubble (or a series of bubbles) has entered the measuring chamber. These bubble events were observed at tributary and occur mainly in summer, being consistent with previous observations of bubble emissions stimulated by declining pressure (McGinnis et al., 2006) as well as the enhanced $\mathrm{CH}_{4}$ production in the sediments due to the higher temperatures (Delsontro et al., 2010). This observation is similar with other research that bubble emissions are a major component of the total flux under particular conditions including dendritic reservoirs with substantial vegetated littoral zones, shallow deltaic deposition zones (DelSontro et al., 2011; Chen et al., 2009) coupled with shallow depths (McGinnis et al., 2006). Thus, the surface emission of $\mathrm{CH}_{4}$ from TGR is confined largely to diffusive fluxes. Meanwhile, as a valley-type reservoir, tributaries in TGR only occupied one third of the total reservoir surface, and regions for potential $\mathrm{CH}_{4}$ bubbles are further limited. Further study is needed to detail the $\mathrm{CH}_{4}$ emission via bubbling and the mechanisms in these tributary regions.

Uncertainties also exist in assessing the net impact on GHG emissions from the creation of TGR. We studied the GHG fluxes from several sites within the reservoir region and also an upstream site (ZT) unaffected by the reservoir; it is possible to assess the difference in GHG fluxes from pre- and post-impoundment waterbodies by treating ZT as a reference site for pre-impoundment (IHA, 2010), which the results have cursorily mentioned in the text. Overall, $\mathrm{CO}_{2}$ fluxes at reservoir mainstream and downstream sites have marginally increased. All the tributary sites, however, have reduced $\mathrm{CO}_{2}$ fluxes compared to the $\mathrm{ZT}$ site. In those tributary regions, the impoundment has converted a rapidly flowing, narrowly confined river into broader, quieter backwa- ter with enhanced uptake of $\mathrm{CO}_{2}$ by riparian vegetation and phytoplankton, thus reducing the overall net $\mathrm{CO}_{2}$ flux, especially during spring and summer. For $\mathrm{CH}_{4}$, fluxes at mainstream sites have significantly reduced when compared with ZT sites. The presence of a well-oxygenated water column and great water depth limited the $\mathrm{CH}_{4}$ fluxes at the surface. The upper reach mainstream sites and tributary stations $\mathrm{CH}_{4}$ emissions are increased, reflecting the increased scope for sedimentation in these areas, and for autochthonous production that contributes to the formation of the anoxic zones. But, to get a reliable estimates of net GHG emissions from TGR, other pre-impoundment natural emissions need to be considered, including terrestrial and other aquatic ecosystems (IHA, 2010).

\section{Conclusions}

The present study has shown that the TGR is generally a source of atmospheric GHG (including $\mathrm{CO}_{2}, \mathrm{CH}_{4}$ and $\mathrm{N}_{2} \mathrm{O}$ ). The GHG budget is estimated to be $1.5 \times 10^{6} \mathrm{tCO}_{2}$, which is negligible when relate to China's national $\mathrm{CO}_{2}$ emissions. This result also indicates that the $\mathrm{CO}_{2}$ emissions from the reservoir are significantly lower than those from other kinds of energy sources like coal, oil and natural gas. In this respect, hydroelectric can be considered a better choice for substitution of traditional energies.

This study has also explored the spatial-temporal patterns of GHG fluxes at TGR. The reservoir surface can sometimes act as a sink for atmospheric $\mathrm{CO}_{2}$, and it mostly happened in the tributary regions like XR in March, June and July. This could likely be attributed to the withdrawal of $\mathrm{CO}_{2}$ by 
photosynthesis in these regions. While in the mainstream, higher temperature and a great amount of allochthonous inputs led to a relatively higher $\mathrm{CO}_{2}$ fluxes in the hot seasons. The data also indicate that fluxes from reservoir surface seemed different from one region to another. Overall, higher $\mathrm{CH}_{4}$ fluxes were spotted in the tributaries, while relatively higher $\mathrm{CO}_{2}$ fluxes were observed at mainstream sites. Therefore, these spatial-temporal characteristics should be taken into account in future studies to further explore the underlying mechanisms controlling GHG emission kinetics, including the potential bubbling events for $\mathrm{CH}_{4}$ at the upper reach of tributaries, flooded organic matter and allochthonous inputs from drawdown areas and so on.

Finally, GHG fluxes from the TGR were compared with other hydroelectric dams around the world, and the results revealed that the TGR's $\mathrm{CO}_{2}$ fluxes are comparable to most temperate hydropower plants, partly due to the high allochthonous organic carbon input from the reservoir catchment. Meanwhile, $\mathrm{CH}_{4}$ fluxes were much lower than tropical hydrosystems, which could be largely explained by the deep water and well-oxygenated water column promoting the dissolution and oxidation of $\mathrm{CH}_{4}$.

\section{Supplementary material related to this article is available online at: http://www.biogeosciences.net/10/ 1219/2013/bg-10-1219-2013-supplement.zip.}

Acknowledgements. This research was jointly supported by the Major State Basic Research Development Program of China (973 Program) (No. 2010CB955904) and Knowledge Innovation Program of the Chinese Academy of Sciences (No. ZNWH2011-014). We appreciate support from Zhiqiang Zhou, and Chao Yuan for participation in the field campaign. We also appreciate Xiaoke Wang, Yuchun Wang, Yonghong Bi, Shangbin Xiao, Jinsong Guo providing field data. We thank P. W. Ford (CSIRO, Australia) for editorial assistance.

Edited by: Z. Jia

\section{References}

Barros, N., Cole, J. J. Tranvik, L. J., Prairie, Y. T., Bastviken, D., Huszar, V. L. M., Giorgio, P. D., and Roland, F.: Carbon emission from hydroelectric reservoirs linked to reservoir age and latitude, Nat Geosci., 4, 593-596, 2011.

Bastviken, D., Ljlertsson, J., and Tranvik, L.: Measurement of methane oxidation in Lakes: A comparison of methods, Environ, Sci. Technol., 36, 3354-3361, 2006.

Bergstrom, I., Makela, S., Kankaala, P., and Kortelainen, P.: Methane efflux from littoral vegetation stands of southern boreal lakes: An upscaled regional estimate, Atmos. Environ., 41, 339-351, 2007.
Chen, H., Wu, Y., Yuan, X., Gao, Y., Wu, N., and Zhu, D.: Methane emissions from newly created marshes in the drawdown area of the Three Gorges Reservoir, J. Geophys. Res., 114, D18301, doi:10.1029/2009JD012410, 2009.

DelSontro, T., Mcginnis, D. F., Sobek, S., Ostrovsky, I., and Wehrli, B.: Extreme methane emissions from a Swiss hydropower reservoir: contribution from bubbling sediments, Environ. Sci. Technol, 44, 2415-2425, 2010.

DelSontro, T., Kunz, M. J., Kempter, T., Wüest, A., Wehrli, B., and Senn, D. B.: Spatial heterogeneity of methane ebullition in a large tropical reservoir. Environ. Sci. Technol., 45, 9866-9873, 2011.

DosSantos, M. A., Rosa, L. P., Sikar, B., Sikar, E., and dosSantos, E. O.: Gross greenhouse gas fluxes from hydro-power reservoir compared to thermo-power plants, Energ. Policy, 34, 481-488, 2006.

Duchemin, E., Lucotte, M., Canuel, R., and Chamberland, A.: Production of the greenhouse gases $\mathrm{CH}_{4}$ and $\mathrm{CO}_{2}$ by hydroelectric reservoir of the boreal region, Global Biogeochem. Cy., 9, 529540, 1995.

Fearnside, P. M.: Greenhouse gas emissions from a hydroelectric reservoir (Brazil's Tucurui Dam) and the energy policy implications, Water Air Soil Pollut., 133, 69-96, 2002.

Fu, B. J., Wu, B. F., Lu, Y. H., Xu, Z. H., Cao, J. H., Niu, D., Yang, G. S., and Zhou, Y. M.: Three Gorges project: efforts and challenges for the environment, Prog. Phys. Geogr., 34, 741-754, 2010.

Giles, J.: Methane quashes green credentials of hydropower, Nature, 444, 524-525, 2006.

Graus, W. H. J., Voogt, M., and Worrell, E.: International comparison of energy efficiency of fossil power generation, Energ. Policy, 35, 3936-3951, 2007.

Guerin, F., Abril, G., and Richard, S.: Methane and Carbon Dioxide emissions from tropical reservoirs: Significance of downstream rivers, Geophys. Res. Lett., 33, L21407, doi:10.1029/2006GL027929, 2006.

Guerin, F., Abril, G., de Junet, A., and Bonnet, M.: Anaerobic decomposition of tropical soils and plant material: Implication for the $\mathrm{CO}_{2}$ and $\mathrm{CH}_{4}$ budget of the Petit Saut Reservoir, Appl. Geochem., 23, 2272-2283, 2008.

Huttunen, J. T., Alm, J., Liikanena, A., Juutinen, S., Larmola, T., Hammar, T., Silvola, J., and Martikainen, P. J.: Fluxes of methane, carbon dioxide and nitrous oxide in boreal lakes and potential anthropogenic effects on the aquatic greenhouse gas emissions, Chemosphere, 52, 609-621, 2003.

International Hydropower Association: GHG measurement guidelines for freshwater reservoirs, Sutton, London, 2010.

James, B. A.: $\mathrm{CO}_{2}$ emissions, research and technology transfer in China, Ecol. Econ., 68, 2658-2665, 2009.

Liu, L., Chen, H., Yuan, X. Z., Chen, Z. L., and Wu, Y. Y.: Unexpected $\mathrm{CH}_{4}$ emission from the Three Gorges Reservoir and its implications, Acta Ecol. Sin., 31, 233-234, 2011.

McGinnis, D. F., Greinert, J., Artemov, Y., and Wüest, A.: Fate of rising methane bubbles in stratified waters: how much methane reaches the atmosphere?, J. Geophys. Res., 111, C09007, doi:10.1029/2005JC003183, 2006.

Oelbermann, M. and Schiff, S. L.: The redistribution of soil organic carbon and nitrogen and greenhouse gas production production rates during reservoir drawdown and reflooding, Soil Sci., 175, 
72-80, 2011.

Qiu, J.: Chinese dam may be a methane menace, Nature, http://www.nature.com/news/2009/090929/full/news.2009. 962.html, doi:10.1038/news.2009.962, 2009.

Rosa, L. P., dosSantos, A. M., Matvienko, B., dosSantos, E. O., and Sikar, E.: Greenhouse gas emissions from hydroelectric reservoirs in tropical regions, Clim. Change, 66, 9-21, 2004.

Sobek, S., DelSontro, T., Wongfun, N., and Wehrli, B.: Extreme organic carbon burial fuels intense methane bubbling in a temperate reservoir, Geophys. Res. Lett., 39, L0141, doi:10.1029/2011GL050144, 2012.

Soumis, N., Duchemin, E., and Lucotte, R. C. A. M.: Greenhouse gas emissions from reservoirs of western United States, Global Biogeochem. Cy., 18, GB3022, doi:10.1029/2003GB002197, 2004.

St. Louis, V. L., Kelly, C. A., Duchemin, E., Rudd, J. W. M, and Rosenberg, D. M.: Reservoir surfaces as sources of greenhouse gases to the atmosphere: a global estimate, Bioscience, 50, 766$775,2000$.

Stone, R.: Three Gorges Dam: Into the Unknown, Science, 321, 628-632, 2008.

Teodoru, C. R., Prairie, Y. T., and Giorgio, P. A. D.: Spatial heterogeneity of surface $\mathrm{CO}_{2}$ fluxes in a newly created Eastmain-1 reservoir in Northern Quebec, Canada, Ecosystems, 14, 28-46, 2011.

Tremblay, A., Varfalvy, L., Roehm, C., and Garneau, M. (Eds.): Greenhouse Gas Emissions - Fluxes and Processes: Hydroelectric reservoirs and natural environments, Springer, 2005.
Vachon, D., Prairie, Y. T., and Cole, J. J.: The relationship between near-surface turbulence and gas transfer velocity in freshwater systems and its implications for floating chamber measurements of gas exchange, Limnol. Oceanogr., 55, 1723-1732, 2010.

Wu, Y., Zhang, J., Liu, S. M., Zhang, Z. F., Yao, Q. Z., Hong, G. H., and Cooper, L.: Sources and distribution of carbon within the Yangtze River system, Estuar. Coast. Shelf Sci., 71, 13-25, 2007.

Xing, Y., Xie, P., Yang, H., Ni, L., Wang, Y., and Rong, K.: Methane and carbon dioxide fluxes from a shallow hypereutrophic subtropical lake in China, Atmos. Environ., 39, 5532-5540, 2005.

Yang, M., Bi, Y. H., Hu, J. L., Zhu, K. X., Zhou, G. J., and Hu, Z. Y.: Seasonal variation in functional phytoplankton groups in Xiangxi Bay, Three Gorges Reservoir, Chin. J.f Oceanol. Limn., 29, 1057-1064, 2011.

Ye, L., Xu, Y. Y., and Han, X. Q.: Daily dynamics of nutrients and chlorophyll a during a spring phytoplankton bloom in Xiangxi Bay of the Three Gorges Reservoir, J. Freshwater Ecol., 21, 315321, 2006.

Ye, L., Han, X. Q., Xu, Y. Y., and Cai, Q. H.: Spatial analysis for spring bloom and nutrient limitation in Xiangxi bay of Three Gorges Reservoir, Environ. Monit. Assess., 127, 135-145, 2007.

Yu, Z. Z. and Wang, L. L.: Factors influencing thermal structure in a tributary bay of Three Gorges Reservoir, J. Hydrodynam., 23, 407-415, 2011.

Zhang, Q. and Lou, Z.: The environmental changes and mitigation actions in the Three Gorges Reservoir region, China, Environ. Sci. Policy, 14, 1132-1138, 2011. 